\title{
Prevalence and Trends in Cigarette Smoking Among Adults with Epilepsy - United States, 2010-2017
}

\author{
Sanjeeb Sapkota MBBS${ }^{1}$; Rosemarie Kobau, $\mathrm{MPH}^{2}$; Janet B. Croft, $\mathrm{PhD}^{2}$; Brian A. King, $\mathrm{PhD}^{3}$; Craig Thomas, PhD²; Matthew M. Zack, $\mathrm{MD}^{2}$
}

Cigarette smoking remains the leading cause of preventable disease and death in the United States (1). Although the percentage of all U.S. adults who smoke cigarettes has declined substantially since the mid-1960s (1,2), marked disparities persist, and declines have not been consistent across population groups $(1,2)$. Studies have shown that cigarette smoking is as common, and sometimes more so, among adults with a history of epilepsy compared with those without a history of epilepsy, but reasons for this are unclear (3-6). Compared with adults without epilepsy, adults with epilepsy report lower household income, more unemployment and disability, worse psychological health, and reduced health-related quality of life $(3,4,6,7)$. Trends in cigarette smoking among U.S. adults with epilepsy have not been previously assessed. CDC analyzed National Health Interview Survey (NHIS) data among 121,497 U.S. adults from 2010, 2013, 2015, and 2017 to assess current cigarette smoking by epilepsy status. From 2010 through 2017, the age-standardized percentages of current smoking were $24.9 \%$ among adults with active epilepsy, $25.9 \%$ among adults with inactive epilepsy, and $16.6 \%$ among adults with no history of epilepsy. After accounting for differences in data collection intervals and patterns in smoking status among subgroups, CDC found that current cigarette smoking declined significantly from 2010 to 2017 among adults with no history of epilepsy $(19.3 \%$ to $14.0 \%$ [p<0.001]) and inactive epilepsy $(29.2 \%$ to $16.2 \%$ [p $=0.03])$, but declines among adults with active epilepsy were not statistically significant $(26.4 \%$ to $21.8 \%$ [ $\mathrm{p}=0.2]$ ). Epilepsy health and social service providers should promote smoking cessation resources to adults with active epilepsy who smoke cigarettes to help them quit smoking and to reduce their risk of smoking-related disease and death.*

NHIS is an annual, nationally representative, in-person survey of the noninstitutionalized U.S. civilian population. The NHIS Sample Adult core questionnaire is administered to a randomly selected adult aged $\geq 18$ years in each family within the selected household. Sample sizes and final response rates for sample adults in each of the 4 years were as follows: 2010 (27,157; 72.1\%), 2013 (34,557; 61.2\%), 2015 (33,672; 55.2\%) and 2017 (26,742; 53.0\%). ${ }^{\dagger}$ Supplementary questions on epilepsy were added to the Sample Adult Core component of NHIS in 2010, 2013, 2015, and 2017.

\footnotetext{
*https://www.cdc.gov/tobacco/quit_smoking/cessation/index.htm.

$\dagger$ ftp://ftp.cdc.gov/pub/Health_Statistics/NCHS/Dataset_Documentation/ NHIS/2017/srvydesc.pdf.
}

Respondents were defined as having "any epilepsy" (either active or inactive epilepsy) or no history of epilepsy based on three questions. ${ }^{\S}$ Those who reported doctor-diagnosed epilepsy and also reported taking antiseizure medication, having one or more seizures in the past year, or both were classified as having "active" epilepsy. Respondents were classified as having "inactive" epilepsy if they reported a history of epilepsy but were not taking medication for epilepsy and had not had a seizure in the past year. Current combustible cigarette smoking was defined as self-reported use of at least 100 cigarettes during the respondent's lifetime and smoking "every day" or "some days" at the time of interview. Current cigarette smoking, by epilepsy status, was assessed overall and by survey year; data from 2010, 2013, 2015, and 2017 were aggregated to provide more stable estimates of current cigarette smoking by sex, age, race/ethnicity, education, family income, ${ }^{* *}$ health insurance coverage at the time of survey, employment status, disability status, U.S. Census region, and presence or absence of serious psychological distress.

SAS (version 9.4; SAS Institute) and SUDAAN (version 11.0; RTI International), which accounted for the respondent sampling weights and the NHIS complex sample design, were used for the analysis. The aggregated analytical sample for this report included 121,497 adults with complete data on epilepsy and current cigarette smoking status. All reported differences among three or more groups were assessed using a Wald F test; differences between two subgroups were assessed using two-tailed t-tests. The threshold for statistical significance for all tests was $\mathrm{p}<0.05$. Orthogonal polynomials, a statistical analysis to examine trends, was used to estimate the decline in percentage of adults who smoked from 2010 to 2017, accounting for unequal data collection intervals and different patterns in smoking prevalence among the three subgroups.

\footnotetext{
$\S$ The questions were asked as follows: "Have you ever been told by a doctor or other health professional that you have a seizure disorder or epilepsy?" Responses included Yes, No, Refused, Not ascertained, and Don't know. If respondents answered "Yes" to having been told that they have seizure disorder or epilepsy, they were also asked "Are you currently taking any medicine to control your seizure disorder or epilepsy?” Responses included Yes, No, Refused, Not ascertained, and Don't know. Respondents who answered "Yes" were also asked "Think back to last year about the same time. About how many seizures of any type have you had in the past year?" Responses included: None, One, Two or three, Between four and 10, More than 10, Refused, Not ascertained, and Don't know.

S Cigarette smoking percentages were age-standardized to the 2000 U.S. projected population.

** Categorized based on the ratio of total family income to the federal poverty level calculated using the NHIS imputed income files.
} 
Among all U.S. adults, $1.1 \%$ had active epilepsy and $0.7 \%$ had inactive epilepsy. Current cigarette smoking prevalence was $24.9 \%$ for adults with active epilepsy, $25.9 \%$ for adults with inactive epilepsy, and $16.6 \%$ for adults without epilepsy (Table). Current cigarette smoking prevalence was higher among adults with active epilepsy than among those with no history of epilepsy overall and for both men and women; adults aged 35-54 or 55-64 years; non-Hispanic Whites and Other, non-Hispanic adults; adults with $<12$ or $>12$ years of education; adults with family incomes $<100 \%$ or $>300 \%$ of the

TABLE. Age-standardized* estimates of current smoking ${ }^{\dagger}$ prevalence among adults, by epilepsy status and selected characteristics — United States, 2010, 2013, 2015 and 2017

\begin{tabular}{|c|c|c|c|c|c|c|}
\hline \multirow[b]{2}{*}{ Characteristic } & \multicolumn{2}{|c|}{ Active epilepsy } & \multicolumn{2}{|c|}{ Inactive epilepsy } & \multicolumn{2}{|c|}{ No history of epilepsy } \\
\hline & No. ${ }^{\S}$ & $\%(95 \% \mathrm{Cl})$ & No. ${ }^{\S}$ & $\%(95 \% \mathrm{Cl})$ & No. ${ }^{\S}$ & $\%(95 \% \mathrm{Cl})$ \\
\hline Total (crude) & 1,372 & $25.2(22.4-28.2)$ & 868 & $26.5(23.1-30.3)$ & 119,257 & $16.3(15.9-16.7)$ \\
\hline Total (age-standardized) & 1,372 & $24.9(22.1-28.0)$ & 868 & $25.9(22.6-29.6)$ & 119,257 & $16.6(16.2-16.9)$ \\
\hline $\begin{array}{l}\text { Sex } \\
\text { Men } \\
\text { Women }\end{array}$ & $\begin{array}{l}607 \\
765\end{array}$ & $\begin{array}{l}24.1(20.0-28.7) \\
25.5(21.9-29.5)\end{array}$ & $\begin{array}{l}345 \\
523\end{array}$ & $\begin{array}{l}27.5(22.3-33.4) \\
25.3(21.2-29.8)\end{array}$ & $\begin{array}{l}53,346 \\
65,911\end{array}$ & $\begin{array}{l}18.5(18.0-19.0) \\
14.7(14.2-15.1)\end{array}$ \\
\hline Age group (yrs) & & & & & & \\
\hline $\begin{array}{l}18-34 \\
35-54 \\
55-64 \\
\geq 65\end{array}$ & $\begin{array}{l}287 \\
503 \\
296 \\
286\end{array}$ & $\begin{array}{r}22.4(16.9-29.1) \\
33.1(28.2-38.5) \\
28.4(22.1-35.7) \\
\quad 7.8(5.1-11.7)\end{array}$ & $\begin{array}{l}241 \\
315 \\
166 \\
146\end{array}$ & $\begin{array}{r}24.8(18.7-32.1) \\
31.7(25.938 .1) \\
25.1(18.6-23.9) \\
15.0(9.7-22.6)\end{array}$ & $\begin{array}{l}31,891 \\
39,089 \\
20,006 \\
28,271\end{array}$ & $\begin{array}{r}17.9(17.3-18.5) \\
18.8(18.2-19.4) \\
17.1(16.4-17.8) \\
8.7(8.2-9.1)\end{array}$ \\
\hline $\begin{array}{l}\text { Race/Ethnicity } \\
\text { White, non-Hispanic } \\
\text { Black, non-Hispanic } \\
\text { Hispanic } \\
\text { Other, non-Hispanic }\end{array}$ & $\begin{array}{r}919 \\
218 \\
145 \\
90\end{array}$ & $\begin{array}{r}27.2(23.8-30.9) \\
16.6(10.9-24.5) \\
14.9(9.6-22.4) \\
32.6(21.7-45.7)\end{array}$ & $\begin{array}{r}610 \\
122 \\
89 \\
47\end{array}$ & $\begin{array}{r}27.1(23.1-31.4) \\
26.6(18.0-37.3) \\
14.1(8.4-22.8) \\
35.7(20.6-54.2)\end{array}$ & $\begin{array}{r}73,561 \\
16,397 \\
19,611 \\
9,688\end{array}$ & $\begin{array}{l}18.8(18.3-19.3) \\
17.2(16.4-18.0) \\
10.8(10.2-11.4) \\
11.8(10.9-12.8)\end{array}$ \\
\hline $\begin{array}{l}\text { Education level (yrs) } \\
<12 \\
12 \\
>12\end{array}$ & $\begin{array}{l}311 \\
415 \\
629\end{array}$ & $\begin{array}{l}34.3(27.5-41.9) \\
25.3(20.4-30.9) \\
20.8(17.2-24.9)\end{array}$ & $\begin{array}{l}141 \\
231 \\
488\end{array}$ & $\begin{array}{l}39.7(30.8-49.3) \\
28.3(22.1-35.6) \\
21.3(17.4-25.9)\end{array}$ & $\begin{array}{l}17,123 \\
30,044 \\
71,614\end{array}$ & $\begin{array}{l}25.3(24.2-26.4) \\
23.9(23.1-24.6) \\
12.0(11.7-12.4)\end{array}$ \\
\hline $\begin{array}{l}\text { Family income } \\
<100 \% \text { of FPL } \\
100 \%-200 \% \text { of FPL } \\
201 \%-300 \% \text { of FPL } \\
>300 \% \text { of } \mathrm{FPL}\end{array}$ & $\begin{array}{l}362 \\
305 \\
145 \\
559\end{array}$ & $\begin{array}{l}35.2(28.8-42.2) \\
26.4(20.3-33.6) \\
28.7(18.9-41.0) \\
18.9(15.0-23.6)\end{array}$ & $\begin{array}{l}173 \\
151 \\
101 \\
443\end{array}$ & $\begin{array}{l}40.7(32.3-49.7) \\
30.9(21.8-41.9) \\
25.2(16.6-36.3) \\
20.9(16.9-25.6)\end{array}$ & $\begin{array}{l}15,019 \\
18,570 \\
15,413 \\
70,254\end{array}$ & $\begin{array}{l}25.9(24.8-26.9) \\
21.3(20.4-22.2) \\
18.1(17.2-18.9) \\
14.2(13.8-14.6)\end{array}$ \\
\hline $\begin{array}{l}\text { Insurance status } \\
\text { Uninsured } \\
\text { Insured }\end{array}$ & $\begin{array}{r}121 \\
1,246\end{array}$ & $\begin{array}{l}35.2(24.5-46.4) \\
24.1(21.1-27.3)\end{array}$ & $\begin{array}{l}126 \\
739\end{array}$ & $\begin{array}{l}40.1(29.9-51.3) \\
23.3(19.9-27.0)\end{array}$ & $\begin{array}{r}16,635 \\
102,206\end{array}$ & $\begin{array}{l}26.1(24.8-27.4) \\
14.7(14.3-15.1)\end{array}$ \\
\hline $\begin{array}{l}\text { Current employment } \\
\text { Employed } \\
\text { Retired } \\
\text { Disabled } \\
\text { Unemployed } \\
\text { Other (e.g., student or homemaker) }\end{array}$ & $\begin{array}{r}375 \\
229 \\
612 \\
66 \\
88\end{array}$ & $\begin{array}{l}17.6(13.4-22.7) \\
29.0(24.3-34.2) \\
41.8(29.2-55.7) \\
21.1(12.3-33.9)\end{array}$ & $\begin{array}{r}410 \\
122 \\
216 \\
55 \\
65\end{array}$ & $\begin{array}{l}21.7(16.8-27.5) \\
67.8(63.3-71.9) \\
32.9(24.9-42.1) \\
35.6(21.5-52.8) \\
23.7(15.0-35.3)\end{array}$ & $\begin{array}{r}70,478 \\
24,358 \\
8,411 \\
5,565 \\
10,394\end{array}$ & $\begin{array}{l}15.1(14.7-15.5) \\
24.7(15.6-36.8) \\
32.8(30.9-34.6) \\
27.2(25.6-28.9) \\
12.8(11.9-13.8)\end{array}$ \\
\hline $\begin{array}{l}\text { U.S. Census region } \\
\text { Northeast } \\
\text { Midwest } \\
\text { South } \\
\text { West }\end{array}$ & $\begin{array}{l}210 \\
301 \\
542 \\
319\end{array}$ & $\begin{array}{c}25.4(19.3-32.6) \\
30.9(24.5-38.2) \\
25.1(20.9-29.7) \\
18.1(13.1-24.5)\end{array}$ & $\begin{array}{l}111 \\
219 \\
323 \\
215\end{array}$ & $\begin{array}{l}25.2(18.2-33.8) \\
27.0(20.6-34.4) \\
26.2(21.0-32.1) \\
22.4(16.1-30.3)\end{array}$ & $\begin{array}{l}19,510 \\
25,860 \\
43,189 \\
30,698\end{array}$ & $\begin{array}{l}14.8(14.1-15.6) \\
19.6(18.8-20.5) \\
17.8(17.1-18.5) \\
13.1(12.5-13.7)\end{array}$ \\
\hline $\begin{array}{l}\text { Serious psychological distress** } \\
\text { No } \\
\text { Yes }\end{array}$ & $\begin{array}{r}1,091 \\
213\end{array}$ & $\begin{array}{l}22.4(19.4-25.6) \\
43.7(34.9-52.9)\end{array}$ & $\begin{array}{r}775 \\
76\end{array}$ & $\begin{array}{l}23.9(20.5-27.7) \\
44.5(30.1-59.9)\end{array}$ & $\begin{array}{r}111,432 \\
4,293\end{array}$ & $\begin{array}{l}15.7(15.4-16.1) \\
38.2(36.3-40.1)\end{array}$ \\
\hline
\end{tabular}

Abbreviations: $\mathrm{Cl}=$ confidence interval; $\mathrm{FPL}=$ federal poverty level.

* Age-standardized to the 2000 U.S. projected population, aged $\geq 18$ years, using four age groups $(18-34,35-54,55-64$, and $\geq 65$ years). All percentages are agestandardized except those for age groups and overall (crude).

† Current smoking was defined by self-report of smoking at least 100 cigarettes during one's lifetime and smoking every day or some days at the time of the interview.

$\S$ Categories in subgroups might not sum to total because of missing responses for some variables.

I Suppressed because relative standard error was $\geq 0.30$.

** Serious psychological distress was defined as a score $\geq 13$ for responses to six questions based on the Kessler psychological distress scale about feelings of hopelessness, sadness, nervousness, restlessness, worthlessness, and feeling like everything is an effort in the past 30 days. Participants were asked to respond on a Likert scale ranging from "None of the time" $(s c o r e=0)$ to "All of the time" (score $=4)$. Responses were summed over the six questions; respondents with a score of $\geq 13$ were coded as having serious psychological distress, and respondents with a score $<13$ were coded as not having serious psychological distress. 
federal poverty level; adults with health insurance; unemployed adults; and adults residing in the Northeast, the Midwest, or the South (Table). Among those without serious psychological distress, current cigarette smoking among adults with active epilepsy was higher $(22.4 \%)$ than it was among adults without epilepsy (15.7\%).

Current cigarette smoking prevalence among adults with inactive epilepsy was higher than that among adults with no history of epilepsy in many of the same subgroups. Current cigarette smoking was also higher among adults with inactive epilepsy than it was among those without epilepsy for any age group; those with $<12$ or $>12$ years of education; those with family incomes $<100 \%$ or $>300 \%$ of the federal poverty level; among both the insured or the uninsured; the employed; the retired; those in other employment categories (e.g., students); and those residing in all U.S. regions. Among adults without serious psychological distress, cigarette smoking prevalence among those with inactive epilepsy was higher than that among those without epilepsy.

Current cigarette smoking declined significantly among adults without a history of epilepsy, from $19.3 \%$ in 2010 to $14.0 \%$ in 2017 ; a $9.3 \%$ decline $(95 \%$ confidence interval $[\mathrm{CI}]=-10.6 \%$ to $-7.9 \%)(\mathrm{p}<0.05)$ and among adults with inactive epilepsy (from 29.2\% to 16.2\%; a 16.6\% decline [95\% $\mathrm{CI}=-31.9 \%$ to $-1.7 \%])(\mathrm{p}=0.03)$ (Figure). However, declines in current cigarette smoking among adults with active epilepsy were not statistically significant (from $26.4 \%$ to $21.8 \%$; a $9.9 \%$ decline $[95 \% \mathrm{CI}=-23.7 \%$ to $3.9 \%])(\mathrm{p}=0.2)$.

\section{Discussion}

During the 4 survey years (2010, 2013, 2015 and 2017), approximately one in four U.S. adults with active or inactive epilepsy currently smoked cigarettes. This finding reinforces the importance of efforts to reduce cigarette smoking among all adults, especially those with any epilepsy.

Differences in current smoking among adults with epilepsy within subgroups generally paralleled those in the general U.S. adult population, with higher prevalences among some racial/ ethnic minorities and those with lower income, a disability, or serious psychological distress (2). Like the general population, adults with epilepsy have reported challenges in maintaining healthful behaviors but might benefit from interventions that increase skills for adopting and maintaining heal thy behaviors (8). Cigarette smoking is especially complex in epilepsy because nicotine and tobacco smoke have both proconvulsant effects (e.g., reducing the anticonvulsive effects of certain antiseizure drugs) and anticonvulsant effects, which has been demonstrated in various human studies and animal models $(5,9)$. Although one study found that smokers with epilepsy were approximately four times more likely to have experienced a

\section{Summary}

What is already known on this topic?

Studies have shown that cigarette smoking is as common, and sometimes more so, among adults with a history of epilepsy as it is among those without a history of epilepsy.

What is added by this report?

During 2010-2017, one in four adults with active or inactive epilepsy were current smokers, compared with one in six persons without epilepsy. Although fewer adults with active epilepsy smoked cigarettes in 2017 than in 2010, this difference was not statistically significant.

What are the implications for public health practice?

Epilepsy health and social service providers should promote smoking cessation resources to adults with active epilepsy who smoke cigarettes to help them quit smoking and reduce their risk for smoking-related disease and death.

seizure in the past year than were nonsmokers with epilepsy, further research is needed to identify associations between seizure control, current smoking, and smoking cessation in representative samples of persons with active epilepsy $(5,9)$.

Possible differences in smoking trends between adults with active and inactive epilepsy might be associated with differences in overall health status, work limitations, and quality of life between these two groups ( 7 ), but this will require further study. Encouraging smoking prevention and cessation among all adults, including those with epilepsy and other population groups with disproportionately higher prevalences of smoking, is critical to reducing their risk of smoking-related disease and death.

The findings in this report are subject to at least six limitations. First, because epilepsy and smoking status were self-reported and not validated by clinical chart review or biochemical testing, these classifications are subject to social desirability bias, interviewer effects, and misclassification of epilepsy. Second, because NHIS excludes institutionalized populations such as the military, detained or incarcerated persons, and nursing home residents, results are not generalizable to these groups. Third, assessment of subgroup differences within a relatively small sample of adults with epilepsy can obscure differences within these populations. Fourth, the NHIS survey response rate has declined from $72 \%$ in 2010 to $53 \%$ in 2017, resulting in increasing nonresponse bias, which might result in less representative samples of U.S. adults with epilepsy participating in NHIS over time. Fifth, assessment of trends in smoking prevalence among those with active epilepsy might have been underpowered because of sample size limitations. Finally, this study assessed cigarettes only, and not other forms of tobacco products; given that nicotine has been found to have both proconvulsant and anticonvulsant effects, further research on any relationship between epilepsy and the use of noncigarette tobacco products, including e-cigarettes, is warranted. 
FIGURE. Age-standardized percentage* of current smoking among adults with active epilepsy, inactive epilepsy, and no history of epilepsy, by survey year — United States, 2010, 2013, 2015, and 2017

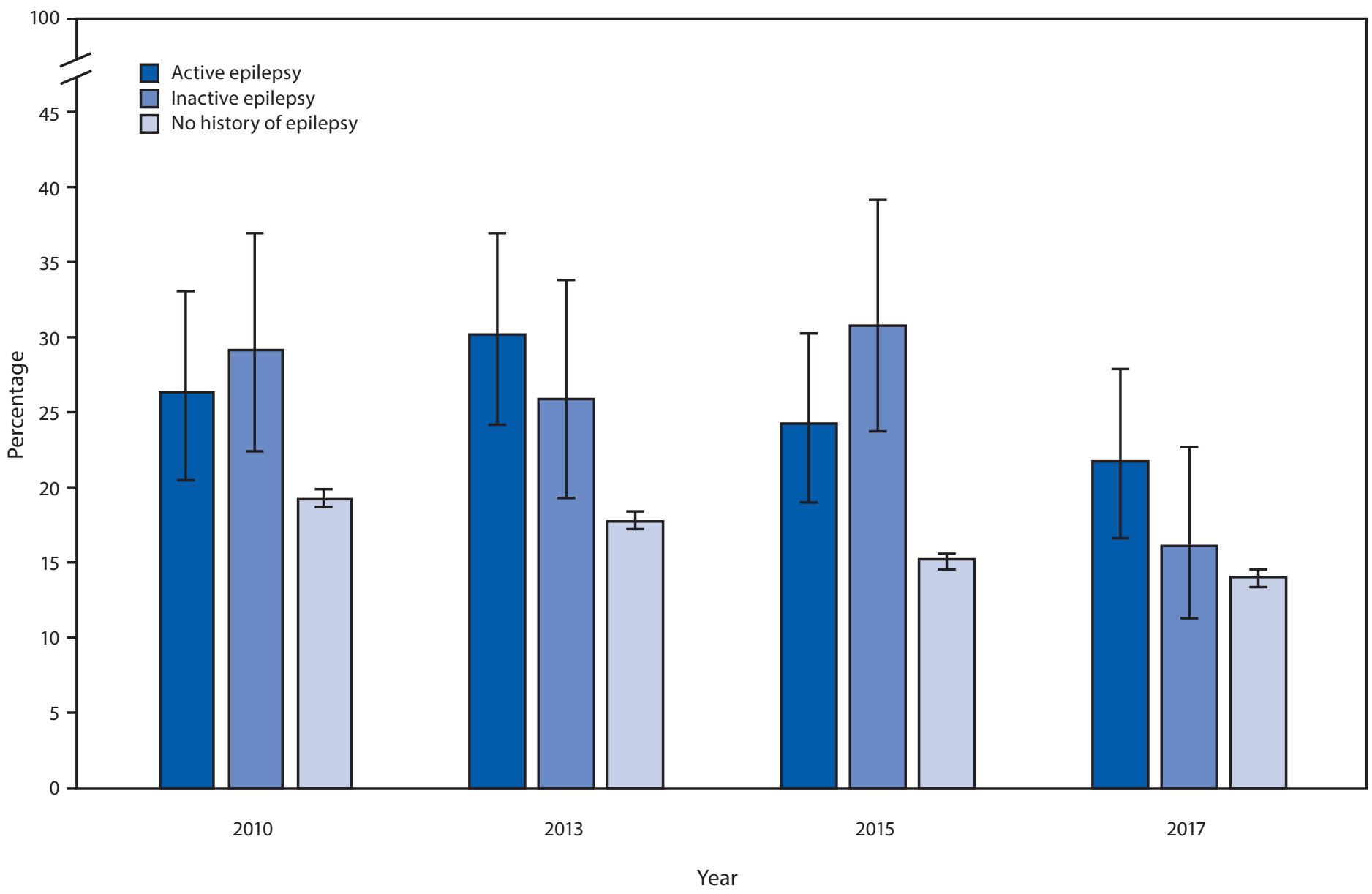

* With $95 \%$ confidence intervals indicated by error bars.

Health and social service providers who interact with persons with active epilepsy should ensure that smoking cessation information and resources are available to them and should encourage persons who smoke to use these resources to help them quit smoking and to reduce their risk of smoking-related disease and death. Funding state tobacco control programs, including state quit lines, at CDC-recommended levels, increasing tobacco prices, implementing comprehensive smoke-free policies, conducting antitobacco mass media campaigns, and enhancing access to quitting assistance could increase tobacco cessation and reduce tobacco-related disease and death among all adults, including those with epilepsy ${ }^{\dagger \dagger}(1,10)$. Insurers and employers could improve coverage and increase use of cessation treatment, and health systems can integrate cessation interventions into clinical care (1).

\footnotetext{
$\dagger_{\dagger}$ https://www.cdc.gov/tobacco/data_statistics/sgr/2020-smoking-cessation/ index.html.
}

\section{Acknowledgment}

Michael Boring, Starr and Associates, Atlanta, Georgia. Corresponding author: Sanjeeb Sapkota, ssapkota@cdc.gov, 770-488-5853.

${ }^{1}$ ASRT Inc., Atlanta, Georgia; ${ }^{2}$ Division of Population Health, National Center for Chronic Disease Prevention and Health Promotion, CDC; ${ }^{3}$ Office on Smoking and Health, National Center for Chronic Disease Prevention and Health Promotion, CDC.

All authors have completed and submitted the International Committee of Medical Journal Editors form for disclosure of potential conflicts of interest. No potential conflicts of interest were disclosed.

\section{References}

1. US Department of Health and Human Services. The health consequences of smoking - 50 years of progress: a report of the Surgeon General. Atlanta, GA: US Department of Health and Human Services, CDC; 2014.

2. Wang TW, Asman K, Gentzke AS, et al. Tobacco product use among adults-United States, 2017. MMWR Morb Mortal Wkly Rep 2018;67:1225-32. PMID:30408019 https://doi.org/10.15585/mmwr. $\mathrm{mm} 6744 \mathrm{a} 2$ 
3. Elliott JO, Moore JL, Lu B. Health status and behavioral risk factors among persons with epilepsy in Ohio based on the 2006 Behavioral Risk Factor Surveillance System. Epilepsy Behav 2008;12:434-44. PMID:18178133 https://doi.org/10.1016/j.yebeh.2007.12.001

4. Elliott JO, Lu B, Moore JL, McAuley JW, Long L. Exercise, diet, health behaviors, and risk factors among persons with epilepsy based on the California Health Interview Survey, 2005. Epilepsy Behav 2008;13:307-15. PMID:18490199 https://doi.org/10.1016/j.yebeh.2008.04.003

5. Johnson AL, McLeish AC, Shear PK, Sheth A, Privitera M. The role of cigarette smoking in epilepsy severity and epilepsy-related quality of life. Epilepsy Behav 2019;93:38-42. PMID:30831400 https://doi. org/10.1016/j.yebeh.2019.01.041

6. Cui W, Zack MM, Kobau R, Helmers SL. Health behaviors among people with epilepsy-results from the 2010 National Health Interview Survey. Epilepsy Behav 2015;44:121-6. PMID:25678033 https://doi. org/10.1016/j.yebeh.2015.01.011
7. Kobau R, Cui W, Kadima N, et al. Tracking psychosocial health in adults with epilepsy-estimates from the 2010 National Health Interview Survey. Epilepsy Behav 2014;41:66-73. PMID:25305435 https://doi. org/10.1016/j.yebeh.2014.08.002

8. Helmers SL, Kobau R, Sajatovic M, et al.; Centers for Disease Control and Prevention Managing Epilepsy Well Network. Self-management in epilepsy: why and how you should incorporate self-management in your practice. Epilepsy Behav 2017;68:220-4. PMID:28202408 https://doi. org/10.1016/j.yebeh.2016.11.015

9. Rong L, Frontera AT Jr, Benbadis SR. Tobacco smoking, epilepsy, and seizures. Epilepsy Behav 2014;31:210-8. PMID:24441294 https://doi. org/10.1016/j.yebeh.2013.11.022

10. CDC. Best practices for comprehensive tobacco control programs-2014. Atlanta, GA: US Department of Health and Human Services, CDC; 2014 